\title{
Four avenues of normative influence: a research agenda for health promotion in low and mid-income countries
}

Cislaghi, Beniamino*

Assistant Professor, London School of Hygiene and Tropical Medicine, United Kingdom

Ben.Cislaghi@1shtm.ac.uk

Heise, Lori

Professor, Johns Hopkins Bloomberg School of Public Health and

Johns Hopkins School of Nursing, Baltimore Maryland.

$\underline{\text { LHeise1@jhu.edu }}$

* Corresponding Author: Ben Cislaghi, London School of Hygiene and Tropical Medicine, Department of Global Health and Development, 15-17 Tavistock Place, WC1H 9SH, London, United Kingdom Ben.Cislaghi@1shtm.ac.uk 


\begin{abstract}
Health promotion interventions in low and mid-income countries (LMIC) are increasingly integrating strategies to change local social norms that sustain harmful practices. However, the literature on social norms and health in LMIC is still scarce. A well-known application of social norm theory in LMIC involves abandonment of female genital cutting (FGC) in West Africa. We argue that FGC is a special case because of its unique relationship between the norm and the practice; health promotion interventions would benefit from a wider understanding of how social norms can influence different types of health-related behaviors. We hypothesize that four factors shape the strength of a norm over a practice: 1) whether the practice is dependent or interdependent; 2) whether it is more or less detectable; 3) whether it is under the influence of distal or proximal norms; and 4) whether non-compliance is likely to result in sanctions. We look at each of these four factors in detail, and suggest that different relations between norms and a practice might require different programmatic solutions. Future findings that will confirm or contradict our hypothesis will be critical for effective health promotion interventions that aim to change harmful social norms in LMIC.
\end{abstract}

Keywords: Social Norms; Social Influence; Behavioral Change; Implementation; Health Promotion; Low and mid-income countries; IPV; FGC; Harmful Practices. 
Four avenues of normative influence: a research agenda for health promotion in low and mid-income countries

In the last decade, individuals working to promote health and eliminate harmful practices in low and mid-income countries (LMIC) have expressed growing interest in new applications of social norms theory. Following the discovery that changing social norms could help people in West and Central Africa abandon female genital cutting (FGC), many development scholars, donors, and practitioners have invested time and resources to understand if and how changing norms through community dialogues can lead to improvements in a wider range of health outcomes. To maximize impact, however, we need to enhance understanding of the different ways in which social norms exert influence on people's action. The norms approach, which was successfully deployed to reduce FGC, may not be equally applicable to other behaviors and practices. Moreover, evidence suggests that failed attempts at norm change might strengthen a norm further. This happens when a few non-compliers try to publicly resist the norm but are sanctioned by those invested in their compliance. Their public failure can diminish chances that people will try to destabilize the norm in the future, afraid of failing and facing similar sanctions (Bettenhausen \& Murnighan, 1985).

Norms are of course but one factor contributing to a given behavior; successful interventions need to address all those factors, a point that we have addressed elsewhere (reference anonymized). In this paper, we look specifically at social norms, offering critical reflections on the different ways in which social norms can influence people's actions. In the first section, we review various norm-related theories and their application to health promotion in LMIC. In the second section, we argue that an "all or nothing" view of normative influence- 
that they either drive behavior or have negligible influence - is not helpful to practitioners. Instead we suggest that norms likely have different levels of influence, based on key characteristics of the behavior under study. In the concluding section, we propose a research agenda to test empirically whether the characteristics we hypothesize as relevant do indeed affect the relationship between norms and health-related behaviors.

\section{Background: Social norms and health promotion in low and mid-income countries}

Social norms-the unwritten rules governing acceptable behavior in a society or a grouphave been the object of much research and practice in the last two decades (Mackie, Moneti, Shakya, \& Denny, 2015; Mollen, Rimal, \& Lapinski, 2010). Although their general influence on people's actions has long been known (Durkheim, 1951; Gibbs, 1965; Hume, [1739] 1978;

Schwartz, 1977; Sumner, 1907), only recently has there been rapid growth in both the scientific literature on health norms (Mollen et al., 2010) and in the number of health-related issues addressed by interventions using social norms approaches (Chung \& Rimal, 2016; Miller \& Prentice, 2016; Tankard \& Paluck, 2016). Research has linked social norms to many healthrelated behaviors, including: food intake (Vartanian, Spanos, Herman, \& Polivy, 2015), alcohol consumption (Prentice \& Miller, 1993; Prestwich et al., 2016), smoking (Eisenberg \& Forster, 2003), use of recreational drugs (Jiloha, 2009; Perkins, 2003), condom use (Hu et al., 2014), physical activity (Ball, Jeffery, Abbott, McNaughton, \& Crawford, 2010), corporal punishment of children (Taylor et al., 2016), intimate partner violence (Linos, Slopen, Subramanian, Berkman, \& Kawachi, 2013), water purification (Mausezahl et al., 2009), and hand washing (Curtis, Danquah, \& Aunger, 2009), to cite just a few examples.

Although there is general agreement that norms influence behavior, there are several different theories on exactly when and how they do so. For instance, in one of the few existing 
reviews of the social norms literature, Bell and Cox (2015) identified four main pathways that help explain people's compliance with social norms: 1) Uncertainty (e.g. I don't know how to behave so I look at what others do and do the same); 2) Identity (e.g. I comply with the norm to express my membership in a group); 3) Reward (e.g. I behave expecting positive sanctions for compliance); and 4) Enforcement (e.g. I am coerced into compliance) (for more reviews see: Brennan, Eriksson, Goodin, \& Southwood, 2013; Chung \& Rimal, 2016; Elsenbroich \& Gilbert, 2014; Lapinski \& Rimal, 2005; Mackie et al., 2015; Morris, Hong, Chiu, \& Liu, 2015; Young, 2015). These theoretical streams further divide into multiple sub-theories, each holding potential value for guiding interventions. In this paper, we use the definition put forward by recent work in social psychology, namely that norms are: 1) beliefs about what others in a given group do (that is, what is typical in the group); and 2) beliefs about what others in a given group approve and disapprove of (that is, what is appropriate in the group) (e.g. Bicchieri, 2006; Cialdini, Kallgren, \& Reno, 1991; Cialdini \& Trost, 1998; Fishbein \& Ajzen, 2010; Gibbs, 1965; Lapinski \& Rimal, 2005; Lewis, 2002; Mackie et al., 2015). While naming conventions for those two types of beliefs differ, most of the contemporary literature follows Cialdini (Cialdini et al., 1991; Cialdini \& Trost, 1998) in referring to the first type as descriptive norms and to the second type as injunctive norms.

Norms exert influence over people's actions in many ways and through many mechanisms, the full review of which goes beyond the scope of this paper (but see: Chung \& Rimal, 2016; C. Horne, 2007; Young, 2015). One of the most commonly cited mechanisms of normative power (and probably one of the strongest) is social influence: compliers are positively sanctioned (praised, accepted in the group, for instance), while non-compliers are negatively sanctioned (gossiped about, isolated, or threatened, for example). People naturally seek rewards 
and avoid punishments. In the case of norms, even the anticipation of potential sanctions is sufficient to keep a social norm locked in place (Bicchieri, 2006; Elster, 2007; Xenitidou \& Edmonds, 2014). For the purpose of the present paper, then, we define social norms as people's beliefs about what others do (descriptive norms) and/or approve of (injunctive norms), held in place, at least in part, by anticipation of positive and negative sanctions.

Cialdini's theory described above was derived from empirical experiments conducted on a wide range of issues in high-income countries, including norms around littering (Cialdini et al., 1991; Keizer, Lindenberg, \& Steg, 2008), towel usage in hotels (Goldstein, Cialdini, \& Griskevicius, 2008), removal of stones from natural parks (Schultz, Nolan, Cialdini, Goldstein, \& Griskevicius, 2007), and college drinking (Prentice \& Miller, 1993). Even though these studies offered ground-breaking contributions to social norm theory, their relevance for the promotion of positive health outcomes in LMIC is still untested.

One practice that has yielded important insights for health promotion in LMIC, is the case of female genital cutting (FGC) in West Africa. Here another theoretical stream of social norms theory, based on game theory, has been used extensively to understand the persistence of FGC, a non-medically justified modification of women's genitalia that poses a global health threat to 140 million women and girls globally (Wagner, 2015). This variant of norms theory is specifically useful when considering interdependent behaviors - those where individuals cannot achieve their objective without coordinating their behaviors with others (Mackie \& LeJeune, 2009; Shell-Duncan, Wander, Hernlund, \& Moreau, 2011). In places where uncircumcised girls are not marriageable (as in Senegal), FGC is a highly interdependent practice. In a seminal article on FGC in West Africa, for instance, Mackie (1996) suggested that since only cut girls are considered pure and marriageable, parents have little choice but to subject their daughters to the 
practice. Even though collective departure from the cutting norm would result in greater health

for all, no single individual or family could depart from the norm without suffering severe consequences (in the case of FGC in Senegal, their daughter not being married).

The norms theory developed by Mackie to explain the persistence of FGC allows for contextual differences: in The Gambia, for instance, Shell-Duncan and colleagues (2011) found stronger normative associations between FGC and social prestige among peers, than FGC and marriageability. While their work confirmed Mackie's theory that FGC can be held in place by a system of norms, it uncovered a different set of social sanctions shared across the group. Mackie found that cutting populations in rural Senegal anticipated marriageability as a positive reward for the cutting; Shell-Duncan and colleagues found that women in Gambia went through the cutting anticipating increased prestige among peers.

\section{The Case of Tostan in West Africa}

Without pre-existing knowledge of social norms theory, but following the insights of local Imam Demba Diawara, the Senegalese NGO Tostan has been able to exploit the interdependent nature of FGC to facilitate its abandonment in rural Senegal. In addition to catalyzing critical reflection through a three-year long educational curriculum, Tostan helps parents (who have learned and discussed the harmful consequences of FGC and are committed to ending the practice) to motivate others in their and the surrounding communities to abandon the practice, making collective, public pledges to leave their daughters intact and to no longer demand circumcision for marriage. Through this means, Tostan is able to reduce FGC by releasing communities from the powerful, interdependent norm that kept the practice in place. Two rigorous evaluations confirmed a reduction in FGC among communities that participated in the Tostan programme (Mackie \& LeJeune, 2009; Young, 2015). 
The success of Tostan in reducing FGC has made its approach to norm change popular in the development sector, where various actors are now applying this model (among others) to problematic norms that sustain harmful gender-related practices (Bajaj, Cislaghi, \& Mackie, 2016; Cislaghi, forthcoming; Cislaghi, Gillespie, \& Mackie, 2016; Jewkes, Flood, \& Lang, 2015; Marcus \& Page, 2014; Powell, 2017; Temmerman, 2015). Tostan's approach is certainly promising: their work has affected a variety of behaviors beyond FGC, including normative change around child marriage. However, one should be careful in translating approaches to norm change based on one practice, to other health-related outcomes. FGC in Senegal presents an almost unique case where the behavior itself is both highly normative and interdependent. Not all health-related related behaviors fulfil these criteria. Exactly how norms influence a healthrelated practice depends in part on the nature of the practice itself, and how norms relate to that practice. Understanding normative influence is thus extremely important for designing effective interventions.

\section{Widening the spectrum of normative influence}

Norms are among the many social processes that influence people's actions, and are very rarely (if ever) the only factor sustaining a practice (e.g. Darnton, 2008; Rimal \& Real, 2003). The strength of their influence can be affected by many factors such as the place and moment that the action is carried out, the nature of the behavior, as well as people's other social and nonsocial (factual) beliefs. There are many different models of how norms can affect attitudes and behaviors (Davis, Campbell, Hildon, Hobbs, \& Michie, 2015). Among the most commonly cited

are: the Theory of Planned Behavior (Fishbein \& Ajzen, 2010); Social Identity Theory (Tajfel \& Turner, 2004); the Focus Theory of Normative Conduct (Kallgren, Reno, \& Cialdini, 2000); and the Theory of Normative Social Behavior (Chung \& Rimal, 2016). Even though they have 
advanced the field considerably, none of these theories offers a device to differentiate among levels of normative strength to inform health promotion interventions.

We propose here a working hypothesis of how normative influence might vary across different health-related practices and contexts. Our hypothesis is informed by the literature and our own personal observations. We are particularly interested in and familiar with the literature on gender-based violence. Comparing FGC with other gender-related harmful practice, we note that four salient characteristics of FGC seem to strengthen the influence of the norm over the practice. Future empirical research will allow us to test whether our theory is relevant only for gender-related practices, other health-related behavior, or neither. The four factors that we hypothesize play a key role in influencing normative strength are: 1) whether the practice is independent or interdependent; 2) whether the practice is detectable or not; 3) whether compliance is subject to weak or strong sanctions and how likely they are; and 4) whether the practice is influenced by distal or proximal norms. We explore each of these factors below.

\section{Independent vs Interdependent}

Researchers have long possessed evidence that people's action are influenced by interaction with others (Lewin, 1948). Investigating how and why people carry out certain social actions — particularly those allowing them to achieve common or collective goals_led Thibaut and Kelley (1959) to expand upon Lewin's observations in their “interdependence theory". Interdependence theory is complex, and includes up to 21 different behavioral patterns (Kelley, 2003). Here, we offer a simplified summary of three main conceptual categories (independent, dependent, and interdependent) for the purposes of our investigation.

Human action varies from highly independent, to dependent, to highly interdependent (Mackie et al., 2015; Thibaut \& Kelley, 1959; Van Lange \& Balliet, 2015). In carrying out an 
independent action, the actor doesn't need to know what others are doing to achieve a desired outcome and, similarly, others don't care about what she is doing. Each can follow their individual preference; a woman living alone, for instance, doesn't need to coordinate with her neighbors to decide whether to brush her teeth before going to bed. One might be tempted to conclude that independent actions are outside of the normative sphere. Instead, we think that norms can still influence independent behaviors, albeit not as strongly as for other types of actions. A fairly independent behavior, blood donation, for instance, has been found to be more strongly influenced by the donators' personal attitude toward donation than descriptive social norms; descriptive norms did have a mild influence, but much less so than the person's individual judgement about the importance of donating blood (Piliavin \& Libby, 1986).

In carrying out a dependent action, one needs to know what others are doing to achieve a given outcome, but others don't care whether or how one might succeed in doing so. Dependence can take many forms (Kelley, 2003). One relevant example is an action carried out to be accepted in a group, so that one conforms with others' actions to obtain their approval. Think of an adolescent boy who recently joined a school and smokes hashish to be accepted by a group of older, popular boys. He needs to mimic what they do, to gain social status, but his decision to comply (or not) might not affect the boys he is trying to impress. Both descriptive and injunctive norms are important in the case of dependent actions: the boy needs to know what the cool boys do (smoking), and what they approve of (him smoking) to be accepted in the group (positive sanction). Much research has been done on the role that norms play in influencing students' smoking and substance use choices. Recent reviews indicate that evidence of normative influence over those behaviors is mixed (Halim, Hasking, \& Allen, 2012; Jiloha, 2009; McAlaney \& Jenkins, 2015; Prestwich et al., 2016). This suggests that dependent actions may 
cover a large part of the normative spectrum, from weaker to stronger influence, and may vary in strength based on context.

Finally, in interdependent actions, a few non-cooperators can compromise the group's goals so that everyone is invested in everyone else's compliance. A classic example of an interdependent action is resource management. Fishermen, for example, need to find cooperative ways to ensure the sustainability of their fishing practices (so that each of them must avoid overfishing) and do so based on reciprocal beliefs that others will respect the norm (Cronk \& Leech, 2013; De, Nau, \& Gelfand, 2016; Mackie et al., 2015; Ostrom, 2014; Young, 2015). When they regulate interdependent practices, people might protect and enforce norms as these norms help them deal with important social problems or dilemmas. In other words, in the case of interdependent practices, the group will actively ensure compliance of a non-complying member, as they are invested in achieving the given outcome (preserving fish stocks, for example) to which the norm contributes and for which group compliance is required.

Sometimes however, interdependent behaviors can be counterproductive to health, as in the case of FGC. When families coordinate to solve the social dilemma of finding an appropriate spouse for their children, they reinforce the harmful norm of genital cutting. Not only do girls' parents have an interest in cutting, but boys' parents do too, because only circumcised girls are considered suitable brides. Compliance with the norm of FGC allows both sets of parents to ensure marriage of their children. People are unlikely to defect from the norm unless they can be assured that their own daughters will not suffer. The only way to break the norm is for everyone to change at once (coordinate), so that a generation of girls remain uncut and will enter the marriage market along with other intact young women (Mackie \& LeJeune, 2009). 


\section{More detectable vs less detectable}

Human beings are highly sensitive to scrutiny. We have an innate tendency to enact prosocial behavior when we believe others are watching. This tendency is so strong that people modify their behavior even when exposed to pictures of eyes on a poster (Bateson, Callow, Holmes, Redmond Roche, \& Nettle, 2013; Nettle et al., 2013), non-human eyes (Haley \& Fessler, 2005), or the abstract representation of a face (Rigdon, Ishii, Watabe, \& Kitayama, 2009). Laboratory experiments suggest that eye gaze influences behavior because it activates one's concerns for his or her reputation (Manesi, Van Lange, \& Pollet, 2016).

The simple reminder that others might know what we are doing may thus act as a deterrent to norm violation. We hypothesize that more detectable practices are likely under stronger normative influence because people anticipate that their compliance or non-compliance will be known by others-either through direct witnessing or indirect testimony (Albarracin et al., 2005; Leung \& Morris, 2014). In an empirical experiment conducted in a public toilet in New York, the simple presence of an observer doubled the percentage of people who washed their hands after having used the toilet (Munger \& Harris, 1989). And ethnographic observations of lobster fishermen in Maine found that, to ensure everyone's compliance with fishing norms, they evolved a system to let non-compliers know that their violation of fishing norms has been detected. They tie a visible piece of cloth to their fishing pots (the first time they transgress) as to say, "I have detected that you are fishing in a place where you are not supposed to, next time you do it we'll kick you out of the group" (Janssen \& Ostrom, 2014).

Compliance with non-detectable practices is less likely to be known by others and is usually under weaker normative influence. Injunctive norms against peeing in the swimming pools exist, but their strength is weakened by the fact that swimmers know that non-compliance 
will go undetected (Brennan et al., 2013; Water Quality and Health Council, 2012). And in a seminal study in 1932, Schanck reported that while residents of Elm Hollow unanimously stated their public support for the Methodist church's prohibition against card playing, smoking, and drinking alcohol, they would do all those things in the privacy of their homes, where others couldn't see them (Schanck, 1932). More recently, a food-behavior experiment at Stanford University revealed that while participating students publicly stated they had changed their food preferences to match those of their peers (from unhealthy to healthful), they still ate as much candy when they thought nobody was watching them (Templeton, Stanton, \& Zaki, 2016).

Some commentators argue that sometimes norms can be internalized, that is, they can influence a person's behavior even when there is no audience to witness it (Andrighetto, Grieco, \& Tummolini, 2015; Elsenbroich \& Gilbert, 2014; Reynolds, Subašić, \& Tindall, 2014; Xenitidou \& Edmonds, 2014). That is possible, especially when norms-complying actions contribute to one's sense of identity (Albarracin et al., 2005; Anderson, 2000; Bardi \& Goodwin, 2011), or when the norm is salient at the time of the action (Cialdini et al., 2006; Keizer et al., 2008). But the opposite can also be true: people might in private consciously behave against the norm, even when they are aware of it, because they hold contrasting values, preferences, or beliefs (Leung \& Morris, 2014). In a seminal study by Deutsch and Gerard (Deutsch \& Gerard, 1955), the researchers found that participants were influenced by norms both in private and public spaces, but that their conformity was higher when their behavior was visible to others. Aware of similar findings, we are not suggesting that norms never exert influence over undetectable practices (if anything we are arguing the opposite); but on a spectrum of normative strength, non-detectable actions might fall closer to the weak-influence end of the spectrum. FGC might fall on the stronger end, as it is often (though not always) celebrated in a public 
ceremony marking girls' passage to womanhood. Halder and colleagues (2015), for instance, reported that the Pokot of Northwest Kenya describe the cutting ceremony as a very attractive and popular event that gathers a crowd of people from neighboring villages. There, the practice is witnessed by many: parents know that their daughter's potential future husbands and his parents will know (or will know someone who knows) if their daughter has been cut or not.

\section{Weak or unlikely vs strong or likely sanctions}

The likelihood of sanctions also varies. Detectability of the norm makes sanctioning possible (others can sanction only if they know of one's non-compliance), but other factors shape how probable it is that people will sanction a behavior. Appropriate sanctioning can be costly, effortful or risky, and people might not be willing to engage in it. One might also refrain from sanctioning because he or she doesn't know other group members well enough to anticipate their reactions. There are also opposite forces pushing for sanctioning: the belief that norms are a common good to be protected; the impulse to protect a group member hurt by the non-complier; the need to demonstrate group identity to others or self; or a spontaneous tendency to gossip and ridicule those who are different from us, for instance (Brennan et al., 2013; Guala, 2012; Christine Horne, 2014).

In addition to being likely or unlikely, sanctions can also be weak or strong; that is, they can result in greater or smaller gains or losses for the person (in the ways they affect economic assets, reputation, emotional wellbeing, or physical health, for instance) (Anderson, 2000). Anticipation of strong sanctions (for instance, losing group membership) will encourage compliance more than anticipation of weak or no sanctions (Mackie et al., 2015; Rimal \& Real, 2003). 
We are not arguing that weak sanctions strip the norm of any influence over behavior. There are many other reasons why people comply with norms: emotional commitment to the group (Tsai \& Bagozzi, 2014); desire to associate with a group identity (Hogg \& Reid, 2006); or simply to know what to do in an ambiguous situation (Rimal \& Real, 2003). But minor improbable sanctions are likely to weaken the overall influence of a norm as compared to strong predictable sanctions.

In the case of FGC, sanctions (e.g. not being able to marry off the uncut girl) are often both strong and likely. They are strong, for instance, in places where girls are considered economically unproductive and marriage becomes a means to transfer an economic burden. They are likely when enforcing them is relatively easy and effortless: often, other parents can simply marry their sons to one of the many circumcised girls of the village (Mackie, 1996, 2015; ShellDuncan et al., 2011).

\section{Proximal vs distal normative influence}

Not much theoretical work has been done on the distinction between what we propose to call proximal and distal norms, especially in the field of health promotion. Proximal norms are those directly related to the behavior in question whereas distal norms are those indirectly related to the practice. Empirical research suggests that salience (the quality of being noticeable) is a central driver of normative compliance (Cialdini et al., 2006; Cislaghi et al., 2016; Keizer, Lindenberg, \& Steg, 2013). Proximal influence is stronger than distal influence, since the proximal norm is salient to those engaging in the practice as they do so. Distal norms, on the other hand, might not be salient at the time of the practice, and might compete with many other indirect social factors and moderators. When they tested the influence of proximal vs distal norms on littering practices, Cialdini and colleagues (1991) found that the proximal norm (you 
shouldn't litter) had the strongest effect on people's actions (not littering); the influence of other distal norms (you should recycle; you should save energy; you should vote) diminished as the distance of these norms from the practice increased. We therefore hypothesize that proximal norms have greater influence on behavior, although more distal norms can still make a difference.

There are two ways, that we identified, in which a norm may relate indirectly to a behavior: either it is more conceptually distant than a norm that directly addresses the behavior in question (as in Cialdini's experiment above); or it is part of a indirect web of norms that do not address the behavior directly, but nonetheless can keep a behavior entrenched. For example, the norm "you should cut your daughter" is proximal to the behavior "cutting your daughter," with the former exerting direct influence over the latter. On the other hand, the norm "a neighbor shouldn't interfere in another family's business" is distal to the behavior "domestic violence," and yet the former might contribute to sustaining the latter, by keeping neighbors from communicating disapproval or intervening to interrupt a violent episode. Norms with no direct relationship to a practice, can nonetheless help sustain it through a different type of distal influence. Norms around maintaining family privacy — as suggested above — might act to perpetuate domestic violence even if there is no norm directly promoting partner violence. People might choose not to intervene when they overhear violence, because they don't think it's acceptable to violate the privacy of the couple. Findings from social norms research on FGC suggest that often the practice is under direct normative influence, since parents cutting their daughters do so because they think others cut and others expect them to cut as well (Mackie, 1996, 2015; Shell-Duncan et al., 2011). Whereas norms sustaining wife beating are subtler, and 
affect the likelihood of surrounding actions: disclosure of violence, seeking help, and others intervening.

\section{A spectrum of normative influence}

We have presented above our hypothesis of four factors that may be critical in influencing the strength of a norm over a practice. These are summarized below in Table 1. We put forward this list to propose a simplified model of how different factors affect a norm's social influence on different health-related practices. More elaborate models of how attributes of norms influence behavior, have been offered elsewhere (Chung \& Rimal, 2016; Jasso \& Opp, 1997; Lascu \& Zinkhan, 1999).

[Table 1 here]

FGC, as described earlier, scores high on this spectrum: it is interdependent, highly detectable, likely to result in strong positive or negative sanctions, and directly under the influence of a norm. Practices and behaviors with these characteristics are likely under strong influence from both descriptive and injunctive norms. The influence of descriptive norms is strengthened by the interdependence of the practice: people need to coordinate or cooperate with others to achieve an outcome, so they plan their actions based on what they believe others do. The influence of injunctive norms is instead strengthened by the detectability of the practice and the likelihood of strong sanctions. People try to avoid strong punishments and seek high rewards (the anticipation of which is based on people's beliefs of what others approve and disapprove of); the detectability of the practice would increase the possibility of incurring in those punishments or rewards. Finally, proximal distance, we hypothesize, exerts strong influence by making both descriptive and injunctive norms more salient; that is, as people perform a given 
action, they are more easily aware of and sensitive to proximal rather than distal norms (see Table 2).

[Table 2 here]

To test the validity of this framework, we need a hypothesis on how descriptive and injunctive norms influence health-related behaviors located at different points on the spectrum. To begin this exploration, we advance here a possible explanation of how descriptive and injunctive norms would influence behaviors at the two (weaker and stronger) ends of the spectrum (summarized in Table 3).

Stronger relation. At the stronger end of the scale, interdependence, detectability, enforcement and normative distance of the practice strengthen the influence of both descriptive and injunctive norms. Carrying out interdependent actions demands compliance with descriptive norms (to coordinate and cooperate I need to know what others are doing). Highly detectable practices incurring heavy sanctions are under stronger influence of injunctive norms (to avoid punishment and obtain rewards I need to know what others approve and disapprove of). Both descriptive and injunctive norms that are proximal will exercise stronger influence than distal norms. Behaviors such as FGC would fall on the right-hand side of the spectrum. Other behaviors such as teen smoking, may meet most but not all of the criteria, landing them nonetheless on a relatively strong end of the spectrum (McAlaney \& Jenkins, 2015). One can imagine, for example, a context where peer pressure to smoke among teens is strong. In this case, the behavior is dependent (an adolescent may need to conform to "belong," but there is not a classic coordination dilemma). The behavior, however, is detectable, subject to sanction (teens who refuse may be ridiculed), and proximal (the perceived norm directly relates to the behavior in question). 
Weaker relation. At this end of the scale, the four factors mention above do not possess enough strength to exercise heavy normative influence. Independent actions can be carried out without considering other people's behavior; compliance with descriptive norms is not necessary to achieve the desired outcome. In the case of undetectable practices incurring light sanctions (if any), injunctive norms are also exerting a weaker influence. Finally, the influence of distal norms might be weakened both by other competing distal factors and by not being salient at the time of the action. Health-related behaviors tending to fall on the weaker end of the spectrum might include: blood donation (Piliavin \& Libby, 1986) and domestic violence (Linos et al., 2013). These practices are mostly independent, only slightly (if at all) detectable, with small (or no) sanctions for non-compliance, and under the influence of bundles of distal norms.

\section{Four avenues of normative influence}

We are not suggesting that weaker normative influence is negligible. There is little doubt that beliefs on what others do and approve of still play a role in people's decision to engage in practices such as donating blood or engaging in domestic violence. Rather, we are arguing that behaviors under stronger normative influence, such as FGC, are carried out primarily to achieve coordination and/or to meet other people's expectations; behavior at the other end of the spectrum is carried out for varied reasons, that may include norms, albeit in a less prominent role.

Differences along this spectrum translate into four types of normative influence (see Table 3). At their strongest, norms prescribe or proscribe obligatory behavior. Actors don't have a choice but to conform, as their compliance allows both them and others to achieve a collective outcome. When they are this powerful, norms shape equilibria, as in the case of FGC, where no actor can deviate from the norm, unless people collectively adopt a new norm. Change strategies 
would require helping people discuss how harmful practices embody collective values (love for children) and goals (getting children married), and identify different social strategies that would still respect their existing values and help them achieve their collective goal, as suggested by Mackie and others in their FGC work (Haylock, Cornelius, Malunga, \& Mbandazayo, 2016; Mackie \& LeJeune, 2009) (see Table 4 for more details on the change strategies).

When they have relatively strong influence, norms define the appropriate behavior. The relative independence of the behavior makes deviation possible but not advisable if one wants to achieve a specific individual outcome. Recall the example of a young student who might feel pressured to smoke marijuana or drink alcohol to be accepted in a group; his doing so or not, however, won't threaten other people's possibility to engage in the behavior (as would be the case with FGC). At this level of normative influence, there might still be normative equilibrium (nobody wants to be the first to stop smoking, worried others will ridicule him), but its strength is weaker than in the previous case, as achieving the independent outcome doesn't require group coordination (as the young adolescent grows up, for instance, he might decide to stop smoking). Change strategies would require facilitating group dialogue on the nature of harm and on reasons for engaging in the practice, aiming at both helping individual resist old expectations and facilitating the emergence of new expectations in the group, as suggested by recent empirical studies of effective social norm change programs (Abramsky et al., 2014; Arango, Morton, Gennari, Kiplesund, \& Ellsberg, 2014; Cislaghi, Gillespie, Fernald, \& Weber, forthcoming; Ensminger \& Kinght, 1997).

\section{[Table 3 here]}

When they have relatively weak influence, norms define what behavior is allowed or tolerated in a group. This is often the case with independent actions carried out in public: they 
are detectable, but there are no or weak sanctions attached to them. Blood donation, for instance, is a detectable practice that might not result in great social rewards or punishment. Or consider a man "catcalling" a woman as he passes by in a car. Even though he might know that observers would disapprove, he may not care because he anticipates few sanctions. Changing strategies at this level of normative influence may include strengthening anticipation of sanctions by strengthening observers' confidence in manifesting their collective disapproval, as suggested by Albaraccin and colleagues in their study of effective measures to increase condom use (Albarracín, Johnson, Fishbein, \& Muellerleile, 2001; Albarracin, Kumkale, \& Johnson, 2004).

Finally, at the weakest level of influence, (the case of undetectable behaviors with no sanctions attached), norms might still offer people a model of behavior that becomes cognitively accessible to them. Social proof (the belief that if many do something, it must be good), and social imitation (the desire to do something just because others are), would both fall within this category. A famous example of this comes from Rubinstein's $(1983,2002)$ seminal work on adolescent suicide in Micronesia. In the early 60s, suicide was almost unknown on the islands in the region, but at the end of the $80 \mathrm{~s}$, its rate was eight times higher than that of the United States. According to Rubinstein (and others who continued in his line of work), one of the reasons explaining the increase was copycatting by other adolescents who wanted to "try it out." (For more examples see: Bollen \& Phillips, 1982; Notredame et al., 2017). Of course, some of these adolescents had also other reasons to commit suicide (as, for instance, intergenerational conflicts: Ran, 2007), but the fact that others were doing it made it imaginable and somehow interesting. Change strategies for norms at this level of influence might include correcting misperceptions and providing individual normative feedback so that people learn that many 
others engage in the positive health behavior of interest, a strategy used widely with university students in high-income countries and particularly the US (Berkowitz, 2014).

[Table 4 here]

While we nod here to the strategies to change norms at each level of the spectrum, it is important to remember that effective behavior change strategies require addressing the full set of the factors that influence behavior, not just the normative element (reference anonymized). In the case of adopting a particular drug, for instance, a person's decision will also be influenced by access to the health care system, provider input, and available resources, to cite just a few additional factors.

\section{Testing the theory of normative spectrum}

Ultimately, the value of our theory will depend on our ability to evaluate its validity through empirical testing. The challenge will be to create metrics to represent the various different dimensions of the theory, from detectability to interdependence, to proximity. One approach would be to apply a modified Delphi method to position behaviors along a continuum of the 5 factors under consideration. The Delphi method is an anonymous method of arriving at consensus by soliciting input through multiple survey rounds, where participants are given feedback on the state of group opinion between each survey round (Hsu \& Sandford, 2007). A behavior or practice could be described in a particular context known to the respondents, and group members would be asked to rank the behavior according to its detectability, likelihood and nature of sanction, whether it is independent, dependent or interdependent, etc. This process would yield a "strength score" suggesting a predicted strength between the norm and the behavior of interest. Investigators could then run a survey to measure the prevalence of the norm 
and the practice in the larger group, testing whether the correlation between the group's normative belief and compliance with the norm is explained by the index of normative strength.

In addition to testing the validity of our hypothesis, future investigations could examine if interdependence, detectability, sanctions, and normative distance have the same strength to influence behavior and how they may interact. Researchers might find, for instance, that interdependence trumps the presence of sanctions, such that a highly-interdependent behavior that is unlikely to encounter sanctions is still under strong normative influence. Doing this would require engaging with the exciting task of reviewing (and potentially developing) measures for the four characteristics we identified (e.g. Labovitz \& Hagedorn, 1973; Rauhut \& Winter, 2010; Singelis, 1994) and then use those measures systematically in a survey or comparable tool, a project that we plan to take forward in the future.

\section{Conclusion}

As practitioners design efforts to use social norm theory to facilitate behavior change, it is important to understand the different ways in which norms might operate. Our paper includes three key messages for scholars and practitioners. The first is that normative change can be an important component of behavior change, although the exact contribution of the former to the latter varies by the strength of the norm and other factors that affect behavior; having tools to understand the strength of the normative is important to design an effective intervention. Even though much of the theoretical work done on norms and health in LMIC is based on findings from FGC, not all practices are under the same normative strength. It would be dangerous to believe that normative change could achieve behavioral change in the same way across different practices. 
Our second message is that it's important to develop a theoretical hypothesis of how norm strength varies; we propose a simple, testable framework that describes the factors that affect normative strength. There is a risk in using intervention approaches that target practices under strong normative influence to address practices under low normative influence. If those latter interventions fail to achieve change in people's behavior, donors and practitioners might conclude that the role of norms is irrelevant. We don't think so. Our hypothesis is that norms can act to hinder or accelerate social change for practices both under stronger and weaker normative influence, but that practitioners must take into account how normative strength interacts with other individual, material, structural, and social factors (Reference anonymized). Effective interventions would thus be integrated, targeting the multiple factors that sustain a harmful practice.

Finally, we suggest that it is misleading to assume (for the purposes of designing interventions) that norms operate similarly with all behaviors, especially given that behaviors vary according to degree of independence, detectability, sanctions, and how directly they relate to the norm. We are confident that practitioners and researchers will find inspiration in this hypothesis as they continue to explore how social norms influence behavior, positioning them to eventually harness the full potential of social norm strategies for protecting and increasing people's health.

\section{Acknowledgments}

We are grateful to Michele Gelfand (University of Maryland), Kees Keizer (University of Groningen), Gerry Mackie (UCSD), Francesca Moneti (UNICEF), Michael Morris (Columbia University), Alina Potts (UNICEF), and Bettina Shell-Duncan (University of Washington) who provided feedback on an early draft of this paper. We are also very grateful to the two 
anonymous reviewers who provided important feedback and helped make the paper more theoretically solid. 


\section{References}

Abramsky, T., Devries, K., Kiss, L., Nakuti, J., Kyegombe, N., Starmann, E., . . Watts, C. (2014). Findings from the SASA! Study: a cluster randomized controlled trial to assess the impact of a community mobilization intervention to prevent violence against women and reduce HIV risk in Kampala, Uganda. BMC Medicine, 12(122). doi:10.1186/s12916014-0122-5

Albarracin, D., Gillette, J. C., Earl, A. N., Glasman, L. R., Durantini, M. R., \& Ho, M. H. (2005). A test of major assumptions about behavior change: a comprehensive look at the effects of passive and active HIV-prevention interventions since the beginning of the epidemic. Psychol Bull, 131(6), 856-897. doi:10.1037/0033-2909.131.6.856

Albarracín, D., Johnson, B. T., Fishbein, M., \& Muellerleile, P. A. (2001). Theories of Reasoned Action and Planned Behavior as Models of Condom Use: A Meta- Analysis. Psychol Bulletin, 127(1), 142-161.

Albarracin, D., Kumkale, G. T., \& Johnson, B. T. (2004). Influences of social power and normative support on condom use decisions: a research synthesis. AIDS Care, 16(6), 700723. doi:10.1080/09540120412331269558

Amal K Halder, Das, S., \& Harun, G. D. (2015). Female Genital Mutilation: From the Life Story of Girls in Remote Villages in Pokot County, Kenya. Journal of Child and Adolescent Behaviour, 3(5), 237-240. doi:10.4172/2375-4494.1000237

Anderson, E. (2000). Beyond Homo Economicus: New Developments in Theories of Social Norms. Philosophy and Public Affairs, 29(2), 170-200.

Andrighetto, G., Grieco, D., \& Tummolini, L. (2015). Perceived legitimacy of normative expectations motivates compliance with social norms when nobody is watching. Frontiers of Psychology, 6, 1413. doi:10.3389/fpsyg.2015.01413

Arango, D. J., Morton, M., Gennari, F., Kiplesund, S., \& Ellsberg, M. (2014). Interventions to Prevent or Reduce VAWG - A Systematic Review of Reviews. Retrieved from http://www.worldbank.org/content/dam/Worldbank/document/Gender/Arango et al 2014. Interventions to Prevent or Reduce VAWG - A Systematic Review of Reviews.pdf

Bajaj, M., Cislaghi, B., \& Mackie, G. (2016). Advancing Transformative Human Rights Education. In G. Brown (Ed.), The Universal Declaration of Human Rights in the 21st Century. Cambridge: OPB.

Ball, K., Jeffery, R. W., Abbott, G., McNaughton, S. A., \& Crawford, D. (2010). Is healthy behavior contagious: associations of social norms with physical activity and healthy eating. International Journal of Behavioral Nutrition and Physical Activity, 7(86). doi:10.1186/1479-5868-7-86

Bardi, A., \& Goodwin, R. (2011). The Dual Route to Value Change: Individual Processes and Cultural Moderators. Journal of Cross-Cultural Psychology, 42(2), 271-287.

Bateson, M., Callow, L., Holmes, J. R., Redmond Roche, M. L., \& Nettle, D. (2013). Do images of 'watching eyes' induce behaviour that is more pro-social or more normative? A field experiment on littering. PLoS One, 8(12), e82055. doi:10.1371/journal.pone.0082055

Bell, D. C., \& Cox, M. L. (2015). Social Norms: Do We Love Norms Too Much? Journal of Family Theory Review, 7(1), 28-46. doi:10.1111/jftr.12059

Berkowitz, A. (2014). The Social Norms Approach.

Bettenhausen, K., \& Murnighan, K. (1985). The Emergence of Norms in Competitive DecisionMaking Groups. Administrative Science Quarterly, 30(1985), 350-372. 
Bicchieri, C. (2006). The Grammar of Society. Cambridge: Cambridge University Press.

Bollen, K. A., \& Phillips, D. P. (1982). Imitative Suicides: A National Study of the Effects of Television News Stories. American Sociological Review, 47(6), 802-809. doi: $10.2307 / 2095217$

Brennan, G., Eriksson, L., Goodin, R. E., \& Southwood, N. (2013). Explaining norms. Oxford: Oxford University Press.

Chung, A., \& Rimal, R. N. (2016). Social Norms: A Review. Review of Communication Research, 2016(4), 1-28. doi:10.12840/issn.2255-4165.2016.04.01.008

Cialdini, R. B., Demaine, L. J., Sagarin, B. J., Barret, D. W., Rhoads, K., \& Winter, P. L. (2006). Managing social norms for persuasive impact. Social Influence, 1(1), 3-15.

Cialdini, R. B., Kallgren, C. A., \& Reno, R. R. (1991). A focus theory of normative conduct: A theoretical refinement and reevaluation of the role of norms in human behavior. Advances in experimental social psychology, 24(20), 1-243.

Cialdini, R. B., \& Trost, M. R. (1998). Social influence: Social norms, conformity and compliance The handbook of social psychology (Vol. II, pp. 367-391.

). New York: McGraw-Hill.

Cislaghi, B. (forthcoming). Human Rights and Community-led Development: Lessons from Tostan. Oxford: EUP.

Cislaghi, B., Gillespie, D., Fernald, A., \& Weber, A. (forthcoming). Senegalese Parents' Beliefs about the Spirit World and their Practices with Infants: A Qualitative Study.

Cislaghi, B., Gillespie, D., \& Mackie, G. (2016). Values Deliberation and Collective Action: Community Empowerment in Rural Senegal. New York: Palgrave MacMillan.

Cronk, L., \& Leech, B. L. (2013). Meeting at Grand Central : understanding the social and evolutionary roots of cooperation. Princeton, N.J. ; Oxford: Princeton University Press.

Curtis, V. A., Danquah, L. O., \& Aunger, R. V. (2009). Planned, motivated and habitual hygiene behaviour: an eleven country review. Health Education Research, 24(4), 655-673. doi:10.1093/her/cyp002

Darnton, A. (2008). Reference Report: An overview of behaviour change models and their uses. Retrieved from http://www.civilservice.gov.uk/wp-content/uploads/2011/09/

Davis, R., Campbell, R., Hildon, Z., Hobbs, L., \& Michie, S. (2015). Theories of behaviour and behaviour change across the social and behavioural sciences: a scoping review. Health Psychol Rev, 9(3), 323-344. doi:10.1080/17437199.2014.941722

De, S., Nau, D., \& Gelfand, M. J. (2016). Using Game Theory to Study the Evolution of Cultural Norms.

Deutsch, M., \& Gerard, H. B. (1955). A study of normative and informational social influences upon individual judgment. Journal of Abnormal and Social Psychology, 51, 629-636.

Durkheim, É. (1951). Suicide : a study in sociology. Glencoe, Illinois: Free Press.

Eisenberg, M. E., \& Forster, J. L. (2003). Adolescent smoking behavior. American Journal of Preventive Medicine, 25(2), 122-128. doi:10.1016/s0749-3797(03)00116-8

Elsenbroich, C., \& Gilbert, N. (2014). Modelling Norms. Amsterdam: Springer Netherlands.

Elster, J. (2007). Explaining Social Behaviour, More Nuts and Bolts for the Social Sciences. Cambridge: Cambridge University Press.

Ensminger, J., \& Kinght, J. (1997). Changing Social Norms: Common Property, Bridewealth, and Clan Exogamy. Current Anthropology, 38(1).

Fishbein, M., \& Ajzen, I. (2010). Predicting and Changing Behavior: The Reasoned Action Approach. New York: Psychology Press. 
Gibbs, J. P. (1965). Norms: The Problem of Definition and Classification. American Journal of Sociology, 70(5), 586-594.

Goldstein, N. J., Cialdini, R. B., \& Griskevicius, V. (2008). A room with a viewpoint: Using social norms to motivate environmental conservation in hotels. Journal of consumer Research, 35(3), 472-482.

Guala, F. (2012). Reciprocity: weak or strong? What punishment experiments do (and do not) demonstrate. Behav Brain Sci, 35(1), 1-15. doi:10.1017/S0140525X11000069

Haley, K. J., \& Fessler, D. M. T. (2005). Nobody's watching? Evolution and Human Behavior, 26(3), 245-256. doi:10.1016/j.evolhumbehav.2005.01.002

Halim, A., Hasking, P., \& Allen, F. (2012). The role of social drinking motives in the relationship between social norms and alcohol consumption. Addict Behav, 37(12), 13351341. doi:10.1016/j.addbeh.2012.07.004

Haylock, L., Cornelius, R., Malunga, A., \& Mbandazayo, K. (2016). Shifting negative social norms rooted in unequal gender and power relationships to prevent violence against women and girls. Gender \& Development, 24(2), 231-244. doi:10.1080/13552074.2016.1194020

Hogg, M. A., \& Reid, S. A. (2006). Social Identity, Self-Categorization, and the Communication of Group Norms. Communication Theory, 16(1), 7-30. doi:10.1111/j.14682885.2006.00003.x

Horne, C. (2007). Explaining Norm Enforcement. Rationality and Society, 19(2), 139-170. doi:10.1177/1043463107077386

Horne, C. (2014). The Relational Foundation of Norm Enforcement. In M. Xenitidou \& B. Edmonds (Eds.), The Complexity of Socia Norms. New York: Springer.

Hsu, C.-C., \& Sandford, B. A. (2007). The Delphi Technique: Making Sense Of Consensus. Pratical Assessment, Research \& Evaluation, 12(10), 1-8.

Hu, Y., Lu, H., Raymond, H. F., Sun, Y., Sun, J., Jia, Y., . . Ruan, Y. (2014). Measures of condom and safer sex social norms and stigma towards HIV/AIDS among Beijing MSM. AIDS Behav, 18(6), 1068-1074. doi:10.1007/s10461-013-0609-7

Hume, D. ([1739] 1978). A treatise of human nature (P. H. Nidditch \& L. A. Selby-Bigge Eds. 2nd ed.). Oxford: Clarendon Press.

Janssen, M., \& Ostrom, E. (2014). Vulnerability of Social Norms to Incomplete Information. In M. Xenitidou \& B. Edmonds (Eds.), The Complexity of Social Norms. New York: Springer.

Jasso, G., \& Opp, K.-D. (1997). Probing the Character of Norms: A Factorial Survey Analysis of the Norms of Political Action. American Sociological Review, 62(6), 947. doi:10.2307/2657349

Jewkes, R., Flood, M., \& Lang, J. (2015). From work with men and boys to changes of social norms and reduction of inequities in gender relations: a conceptual shift in prevention of violence against women and girls. The Lancet, 385(9977), 1580-1589. doi:10.1016/s0140-6736(14)61683-4

Jiloha, R. C. (2009). Social and Cultural Aspects of Drug Abuse in Adolescents. Delhi Psychiatric Journal, 12(2), 167-175.

Kallgren, C. A., Reno, R. R., \& Cialdini, R. B. (2000). A Focus Theory of Normative Conduct: When Norms Do and Do not Affect Behavior. Personality and Social Psychology Bulletin, 26(8), 1002-1012. doi:10.1177/01461672002610009 
Keizer, K., Lindenberg, S., \& Steg, L. (2008). The spreading of disorder. Science, 322(5908), 1681-1685. doi:10.1126/science.1161405

Keizer, K., Lindenberg, S., \& Steg, L. (2013). The importance of demonstratively restoring order. PLoS One, 8(6), e65137. doi:10.1371/journal.pone.0065137

Kelley, H. H. (2003). An atlas of interpersonal situations. Cambridge: Cambridge University Press.

Labovitz, S., \& Hagedorn, R. (1973). Measuring Social Norms. The Pacific Sociological Review, 16(3), 283-303.

Lapinski, M. K., \& Rimal, R. N. (2005). An Explication of Social Norms. Communication Theory, 15(2), 127-147.

Lascu, D.-N., \& Zinkhan, G. (1999). Consumer Conformity: Review and Applications for Marketing Theory and Practice. Journal of Marketing Theory and Practice, 7(3), 1-12. doi:10.1080/10696679.1999.11501836

Leung, K., \& Morris, M. W. (2014). Values, schemas, and norms in the culture-behavior nexus: A situated dynamics framework. Journal of International Business Studies, 46(9), 10281050. doi:10.1057/jibs.2014.66

Lewin, K. (1948). Resolving social conflicts : selected papers on group dynamics. New York: Harper.

Lewis, D. (2002). Convention: A Philosophical Study. Oxford: Blackwell.

Linos, N., Slopen, N., Subramanian, S. V., Berkman, L., \& Kawachi, I. (2013). Influence of Community Social Norms on Spousal Violence: A Population-Based Multilevel Study of Nigerian Women. American Journal of Public Health, 103(1).

Mackie, G. (1996). Ending Footbinding and Infibulation: A Convention Account. American Sociological Review, 61(6), 999-1017.

Mackie, G. (2015). Effective Rule of Law Requires Construction of a Social Norm of Legal Obedience. In C. Tognato (Ed.), Rethinking Cultural Agency: The Significance of Antanas Mockus. Cambridge: Harvard University Press.

Mackie, G., \& LeJeune, J. (2009). Social Dynamics of Abandonment of Harmful Practices: a New Look at the Theory (Vol. 2009-06). Florence: Innocenti Research Centre.

Mackie, G., Moneti, F., Shakya, H., \& Denny, E. (2015). What are Social Norms? How are they measured? UNICEF and UCSD. New York. Retrieved from https://www.unicef.org/protection/files/4 0930 Whole What are Social Norms.pdf

Manesi, Z., Van Lange, P. A. M., \& Pollet, T. V. (2016). Eyes Wide Open: Only Eyes That Pay Attention Promote Prosocial Behavior. Evolutionary Psychology, 14(2). doi: $10.1177 / 1474704916640780$

Marcus, R., \& Page, E. (2014). Changing discriminatory norms affecting adolescent girls through communication activities. Retrieved from London:

Mausezahl, D., Christen, A., Duran Pacheco, G., Tellez, F. A., Iriarte, M., Zapata, M. E., .. . Colford, J. M. J. (2009). Solar Drinking Water Disinfection (SODIS) to Reduce Childhood Diarrhoea in Rural Bolivia: A Cluster-Randomized, Controlled Trial. PLoS Medicine, 6(8).

McAlaney, J., \& Jenkins, W. (2015). Perceived social norms of health behaviours and college engagement in British students. Journal of Further and Higher Education, 1-15. doi:10.1080/0309877x.2015.1070399

Miller, D. T., \& Prentice, D. A. (2016). Changing Norms to Change Behavior. Annu Rev Psychol, 67, 339-361. doi:10.1146/annurev-psych-010814-015013 
Mollen, S., Rimal, R. N., \& Lapinski, M. K. (2010). What is normative in health communication research on norms? A review and recommendations for future scholarship. Health Communication, 25(6-7), 544-547. doi:10.1080/10410236.2010.496704

Morris, M. W., Hong, Y.-y., Chiu, C.-y., \& Liu, Z. (2015). Normology: Integrating insights about social norms to understand cultural dynamics. Organizational Behavior and Human Decision Processes, 129, 1-13. doi:10.1016/j.obhdp.2015.03.001

Munger, K., \& Harris, s. J. (1989). Effects of an observer on handwashing in a public restroom. Perceptual and Motor Skills, 69, 733-734.

Nettle, D., Harper, Z., Kidson, A., Stone, R., Penton-Voak, I. S., \& Bateson, M. (2013). The watching eyes effect in the Dictator Game: it's not how much you give, it's being seen to give something. Evolution and Human Behavior, 34(1), 35-40. doi:10.1016/j.evolhumbehav.2012.08.004

Notredame, C.-E., Pauwels, N., Walter, M., Danel, T., Nandrino, J.-L., \& Vaiva, G. (2017). Why Media Coverage of Suicide May Increase Suicide Rates: An Epistemological Review. In T. Niederkrotenthaler \& S. Stack (Eds.), Media and Suicide: International Perspectives on Research, Theory, and Policy. New York: Routledge.

Ostrom, E. (2014). Collective action and the evolution of social norms. Journal of Natural Resources Policy Research, 6(4), 235-252. doi:10.1080/19390459.2014.935173

Perkins, H. W. (2003). The social norms approach to preventing school and college age substance abuse : a handbook for educators, counselors, and clinicians. San Francisco: Jossey-Bass.

Piliavin, J. A., \& Libby, D. (1986). Personal Norms, Perceived Social Norms, and Blood Donation. Humboldt Journal of Social Relations, 13(1/2).

Powell, K. (2017). A nagging persistence. Nature Human Behaviour, 1(1), 0026. doi:10.1038/s41562-016-0026

Prentice, D. A., \& Miller, D. T. (1993). Pluralistic ignorance and alcohol use on campus: Some consequences of misperceiving the social norm. Journal of Personality and Social Psychology(64), 243-256.

Prestwich, A., Kellar, I., Conner, M., Lawton, R., Gardner, P., \& Turgut, L. (2016). Does changing social influence engender changes in alcohol intake? A meta-analysis. Journal of Consulting and Clinical Psychology, 84(10), 845-860.

Ran, M.-S. (2007). Suicide in Micronesia: A Systematic Review. Primary Psychiatry, 14(11), 80-87.

Rauhut, H., \& Winter, F. (2010). A sociological perspective on measuring social norms by means of strategy method experiments. Social Science Research, 39(6), 1181-1194. doi:10.1016/j.ssresearch.2010.06.009

Reynolds, K. J., Subašić, E., \& Tindall, K. (2014). The Problem of Behaviour Change: From Social Norms to an Ingroup Focus. Social and Personality Psychology Compass, 1-12. doi:10.1111/spc3.12155

Rigdon, M., Ishii, K., Watabe, M., \& Kitayama, S. (2009). Minimal Social Cues in the Dictator Game. Journal of Economic Psychology, 30, 358-367.

Rimal, R. N., \& Real, K. (2003). Understanding the Influence of Perceived Norms on Behaviors. Communication Theory, 13(2), 184-203.

Rubinstein, D. H. (1983). Epidemic Suicide Among Micronesian Adolescents. Social Science and Medicine, 17(10), 657-665. 
Rubinstein, D. H. (2002). Youth Suicide and Social Change in Micronesia. Kagoshima University Occasional Papers, 36, 36-41.

Schanck, R. L. (1932). A study of a community and its groups and institutions conceived of as behaviors of individuals. Princeton, NJ: Psychological Review Co.

Schultz, P. W., Nolan, J. M., Cialdini, R. B., Goldstein, N. J., \& Griskevicius, V. (2007). The constructive, destructive, and reconstructive power of social norms. Psychol Sci, 18(5), 429-434. doi:10.1111/j.1467-9280.2007.01917.x

Schwartz, S. H. (1977). Normative Influences on Altruism. Advances in experimental social psychology, 10, 221-279. doi:10.1016/s0065-2601(08)60358-5

Shell-Duncan, B., Wander, K., Hernlund, Y., \& Moreau, A. (2011). Dynamics of change in the practice of female genital cutting in Senegambia: testing predictions of social convention theory. Soc Sci Med, 73(8), 1275-1283. doi:10.1016/j.socscimed.2011.07.022

Singelis, T. M. (1994). The Measurement of Independent and Interdependent Self-Construals. Personality and Social Psychology Bulletin, 20(5), 580-591. doi:10.1177/0146167294205014

Sumner, W. G. (1907). Folkways; a study of the sociological importance of usages, manners, customs, mores, and morals. Boston,: Ginn.

Tajfel, H., \& Turner, J. C. (2004). The social identity theory of intergroup behavior. In J. T. Jost \& J. Sidanius (Eds.), Political psychology: Key readings (pp. pp. 276-293). New York: Psychology Press.

Tankard, M. E., \& Paluck, E. L. (2016). Norm Perception as Vehicle for Social Change. Social Issues and Policy Review, 10(1), 181-211.

Taylor, C. A., Al-Hiyari, R., Lee, S. J., Priebe, A., Guerrero, L. W., \& Bales, A. (2016). Beliefs and ideologies linked with approval of corporal punishment: a content analysis of online comments. Health Education Research. doi:10.1093/her/cyw029

Temmerman, M. (2015). Research priorities to address violence against women and girls. The Lancet, 385(9978), e38-e40. doi:10.1016/s0140-6736(14)61840-7

Templeton, E. M., Stanton, M. V., \& Zaki, J. (2016). Social Norms Shift Preferences for Healthy and Unhealthy Foods. PLoS One, 11(11), e0166286. doi:10.1371/journal.pone.0166286

Thibaut, J. W., \& Kelley, H. H. (1959). The social psychology of groups. New York: Wiley.

Tsai, H.-T., \& Bagozzi, R. P. (2014). Contribution behavior in virtual communities: cognitive, emotional, and social influences. MIS Quarterly, 38(1), 143-163.

Van Lange, P. A. M., \& Balliet, D. (2015). Interdependence theory. In M. Mikulincer \& P. R. Shaver (Eds.), APA Handbook of Personality and Social Psychology (Vol. 3rd, pp. 6592). Washington, DC: APA.

Vartanian, L. R., Spanos, S., Herman, C. P., \& Polivy, J. (2015). Modeling of food intake: a meta-analytic review. Social Influence, 10(3), 119-136. doi:10.1080/15534510.2015.1008037

Wagner, N. (2015). Female Genital Cutting and Long-Term Health Consequences - Nationally Representative Estimates across 13 Countries. The Journal of Development Studies, 1-21. doi:10.1080/00220388.2014.976620

Water Quality and Health Council. (2012). Swimmer Hygiene Omnibus Survey Results. Retrieved from http://healthypools.org/files/WQHC swimmer hygiene survey results.pdf

Xenitidou, M., \& Edmonds, B. (Eds.). (2014). The Complexity of Social Norms. New York: Springer. 
Young, H. P. (2015). The Evolution of Social Norms. Annual Review of Economics, 7(1), 359387. doi:10.1146/annurev-economics-080614-115322 